\title{
Removal of NO Research in A Polypropylene Hollow Fiber Membrane Contactor
}

\author{
Ying Wang ${ }^{1,}$, ,Xinhai $\mathrm{Yu}^{2, \mathrm{~b}}$ \\ ${ }^{1,2}$ Key Laboratory of Pressure Systems and Safety (MOE), School of Mechanical Engineering, East \\ China University of Science and Technology, Shanghai 200237, China \\ a1569763619@qq.com, byxhh@ecust.edu.cn
}

\begin{abstract}
Keywords:Denitration; Oxidation-absorption; Membrane contactor; $\mathrm{H}_{2} \mathrm{O}_{2}$; Solubility. Abstract.Development of cost-efficient denitration technologies has been a challenging task in industry. Here we proposed a new denitration method by using polypropylene hollow fiber membrane contactor. The NO gas from a simulative flue gas was absorbed into a saline aqueous solution through a holly fiber membrane, and then oxidized by the added $\mathrm{H}_{2} \mathrm{O}_{2}$ in the solution. We examined the effects of different operation parameters including the gas and liquid flow rates, the concentrations of $\mathrm{H}_{2} \mathrm{O}_{2}$ in the solution and $\mathrm{SO}_{2}$ in the mimic flue gas and the circulating time. The optimal operation parameters were identified. Finally, we make a conclusion that by using a PP hollow fiber membrane contactor and $\mathrm{H}_{2} \mathrm{O}_{2}$ aqueous solution with the addition of $\mathrm{NaCl}$, is a new and effective method to remove NO.
\end{abstract}

\section{Introduction}

Nitrogen oxides (NOx), referring to the mixture of $\mathrm{NO}$ and $\mathrm{NO}_{2}$, are essentially formed in all combustion processes. The emission of NOx becomes a serious global environmental problem because NOx represents a key ingredient of photochemical smog and it accounts for about half of all acid deposition [1].

Many of those present technologies have been developed to reduce the NOx emission. For example, there are several methods about the reduction of NOx generation, such as SCR, SNCR, low NOx burners, flue gas recirculation, and low excess air, but they may reduce the reaction efficiency and increase the cost of the combustion system[2]. Membrane gas absorption technology is a hybrid process that it completely integrates the advantages of membrane separation and absorption processes. The liquid flowing in the hollow fiber membrane contactors provides selective absorption to certain gas species, while the porous membrane acts as the contacting interface between the liquid and gas phases, allowing for the unidirectional transport of gas into liquid. Namely, the gas component to be removed is absorbed into the solution when the gas stream contacts with the liquid phase flowing on the other side of the membrane fibers. This technology has been widely adopted for acid gases removal due to its flexible operation, high surface-area-to-volume ratio, compact size, easily linear scale up or down, modularity and other benefits $[3,4,5,6]$. Because of its excellent mass transfer properties, the membrane gas absorption technology may provide one of the most promising alternatives to the conventional technologies for NOx mitigation. However, little study can be found in the literature.

In this work, a membrane system for gas absorption was set up for the NO removal by using a polyproepylne (PP) hollow fiber membrane contactor as the absorber. To enhance the NO solubility, $\mathrm{NaCl}$ was firstly added into the $\mathrm{H}_{2} \mathrm{O}_{2}$ aqueous solution. These effects of operation parameters such as liquid flow rate, gas flow rate, gas composition, the concentrations of $\mathrm{H}_{2} \mathrm{O}_{2}$ and $\mathrm{SO}_{2}$ were investigated and discussed. We also do the long-term operation with the absorbent recycling.

\section{Experimental}

\section{Materials}

The HY/T 110-2008 type porous and hydrophobic PP hollow fiber membrane module (obtained from 718th Institute of China Shipbuilding Industry Corporation) was used as the membrane contactor. The specifications of the hollow fiber membrane module are listed in Table 1. Two gas cylinders 
were used to provide the test gas: 190 ppm $\mathrm{NO}$ balanced with $\mathrm{N}_{2}$, and $1.95 \% \mathrm{SO}_{2}$ balanced with $\mathrm{N}_{2}$ obtained from Shanghai Wetry Standard Gas Co., Ltd. The $\mathrm{H}_{2} \mathrm{O}_{2}$ of $30 \%$ analytical grade (Shanghai Ling Feng Chemical Co., Ltd., China) and analytical-grade $\mathrm{NaCl}$ (Sino pharm Chemical Reagent Co., Ltd.) were dissolved in deionized water to prepare the aqueous solution, which served as the absorbent liquid in the membrane contactor.

Table 1. Specifications of the hollow fiber membrane module.

\begin{tabular}{ll}
\hline Parameter & Value \\
\hline Module outer diameter $(\mathrm{mm})$ & 50 \\
Module inner diameter $(\mathrm{mm})$ & 42 \\
Module length $(\mathrm{mm})$ & 440 \\
Fiber inner diameter $(\mathrm{mm})$ & 0.26 \\
Fiber outer diameter $(\mathrm{mm})$ & 0.38 \\
Fiber length $(\mathrm{mm})$ & 440 \\
Number of fibers & 3000 \\
Fiber porosity & 0.45 \\
Pore size $(\mathrm{m})$ & 0.15 \\
\hline
\end{tabular}

\title{
Experimental apparatus and procedures
}

\author{
(a)
}
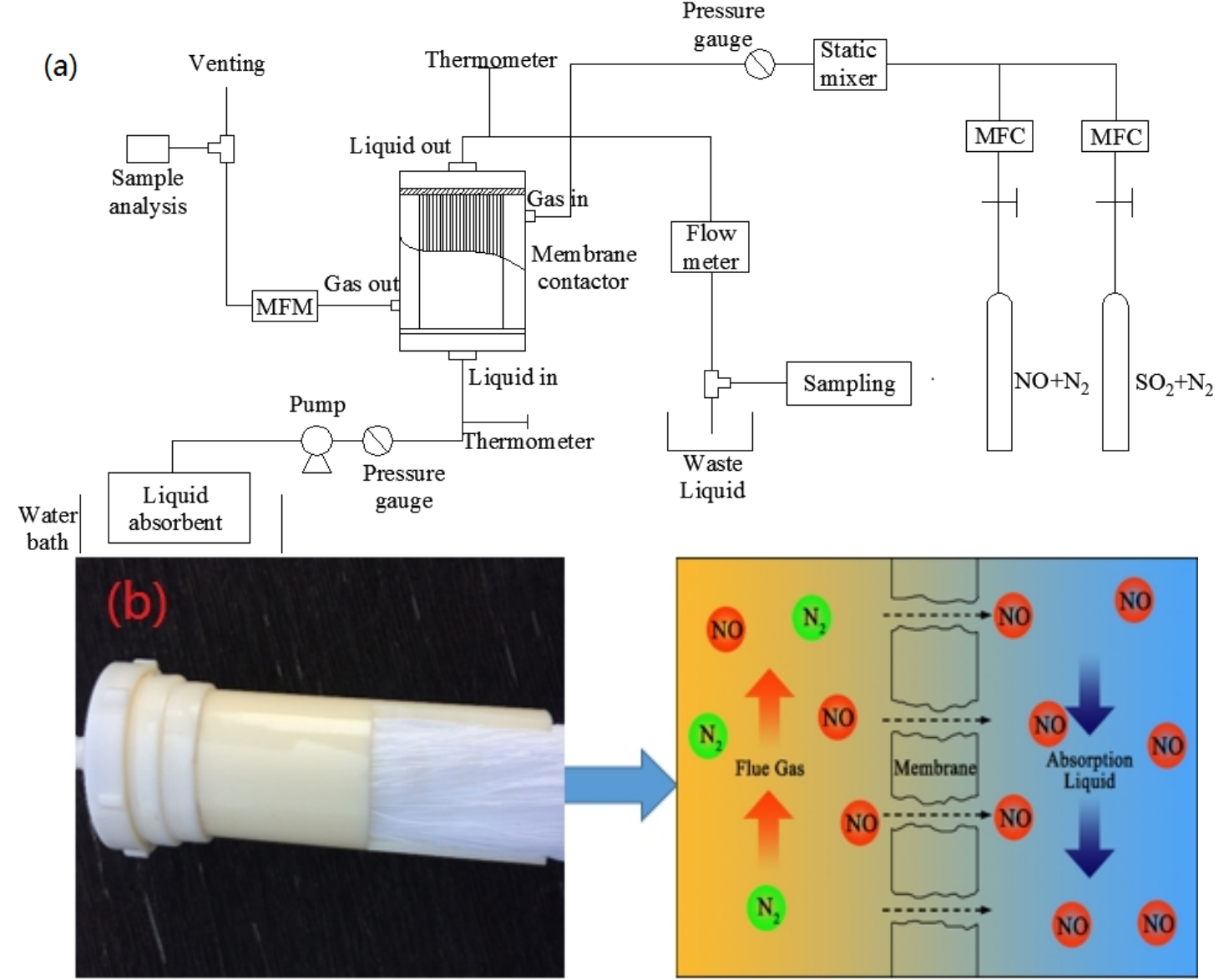

Fig. 1. (a) Schematic diagram of experimental setup for NO removal using a membrane contactor. (b)Principle of NO removal using a membrane contactor.

In the membrane contactor, the feed gas flow and absorbent liquid flow run on the both sides of the membrane. The membrane is selected so that the gas molecules can penetrate through the membrane while the liquid molecule cannot. During this process, the permeated gas molecules continue dissolving into the aqueous solution and reacting with $\mathrm{H}_{2} \mathrm{O}_{2}$. The flow chart of system setup for the NO absorption and reaction is displayed in Fig. 1. These gases from the two cylinders were mixed to form the feed gas, which has the concentration of NO around $200 \mathrm{ppm}$, similar to that in the flue gas after desulfurization. In this work, $\mathrm{CO}_{2}$ and $\mathrm{O}_{2}$ are not involved since they have little impact on the reaction according to our test experiments. The flow rate of the gas at the outlet was measured by a 
mass flow meter (Seven Star Electronics Co., Ltd.) after dehydration. The NO concentration was measured by using a real-time $\mathrm{NO}$ analyzer (CLD 60, Chemiluminescence NO/NO ${ }_{\mathrm{X}}, \mathrm{ECO}$ PHYSICS Analyzer), and the $\mathrm{SO}_{2}$ concentration was analyzed by $\mathrm{SO}_{2}$ detector tubes (No. 5LC Gastec Co., Ltd.).

A stainless steel peristaltic pump (Tian Li liquid Industrial Equipment Factory) was used to pump the absorbent solution into the lumen side of the hollow fibers from a container, and the flow rate of liquid was controlled by a rotational flow meter. The absorbent container was immersed in a water batch (CU-600, Shanghai Precision Instruments Co., Ltd.), to control the temperature of the absorbent solution. The absorption temperature was calculated by taking average of the temperatures at the inlet and outlet of the absorbent solution measured by K-type thermocouples.

All data were collected at steady states, which were achieved after 30min of operation, when the NO concentration in the outlet gas didn't change with time. Each experiment was repeated for 5 times and the average values were reported.

\section{Results and discussion}

In this study, the removal efficiency and mass transfer rate of NO were used to evaluate the separation performance of hollow fiber membrane module, and they can be evaluated in inEqs. (1)and Eqs. $(2)[5,6]$ :

$$
\begin{aligned}
& \eta=\frac{Q_{\text {in }} \times C_{i n}-Q_{o u t} \times C_{o u t}}{Q_{\text {in }} \times C_{\text {in }}} \times 100 \%(1) \\
& J_{\text {gas }}=\frac{\left(Q_{\text {in }} \times C_{\text {in }}-Q_{o u t} \times C_{o u t}\right) \times 273.15}{0.0224 \times T \times S}(2)
\end{aligned}
$$

where $\eta$ denotes the NO removal efficiency, \%; $J_{\text {gas }}$ is the NO mass transfer rate, $\mathrm{mol} \mathrm{m}^{2} \mathrm{~s}^{-}{ }^{1} ; Q_{\text {in }}$ and $Q_{\text {out }}$ represent the inlet and outlet feed gas flow rate, respectively, $\mathrm{m}^{3} \mathrm{~h}^{-1} ; C_{\text {in }}$ and $C_{\text {out }}$ are the NO volumetric fraction at the gas inlet and outlet, respectively, $\%$; $S$ represents the gas-liquid mass transfer area and herein equals to the effective membrane area, $\mathrm{m}^{2}$.

\section{Effect of gas flow rate}

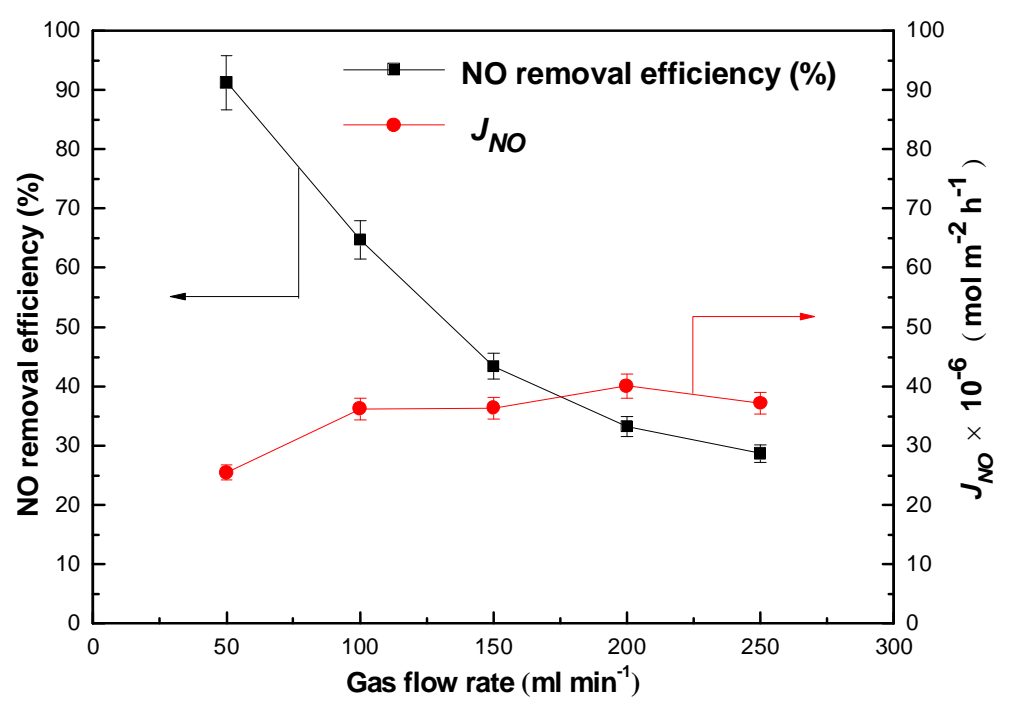

Fig. 2. Effect of gas flow rate on the NO removal efficiency and NO mass transfer rate (feed gas of 184.8 ppm NO balanced with $\mathrm{N}_{2}$; absorbent of $0.2 \mathrm{wt} . \% \mathrm{H}_{2} \mathrm{O}_{2}$ and $5 \mathrm{wt}$. \% NaCl; absorbent flow rate of $40 \mathrm{ml} \mathrm{min}^{-1}$; absorption temperature of $323 \mathrm{~K}$ ). 
Fig. 2 shows the NO removal efficiency dropped continuously and remarkably with the increase in gas flow rate from 50 to $250 \mathrm{ml} \mathrm{min}{ }^{-1}$, coupled with a slight increase in the mass transfer rate. The mass transfer process consists of three consecutive steps: (i) diffusion from the bulk gas phase to the outer surface of the membrane; (ii) diffusion through membrane pores; and (iii) dissolution into the absorption liquid and liquid phase diffusion/chemical reaction. Consequently, for a hydrophobic hollow fiber membrane with gas-filled pores and liquid absorbent in the lumen side, the overall gas phase mass transfer coefficient $\left(k_{0}\right)$ can then be expressed by a resistance in series model[7], as described inEqs. (3):

$$
k_{o}^{-1}=\left(k_{g} \cdot \frac{d_{o}}{d_{i}}\right)^{-1}+\left(k_{m} \cdot \frac{d_{l m}}{d_{i}}\right)^{-1}+H\left(E \cdot k_{l}\right)^{-1} \cdot(3)
$$

For the gas absorption, the resistance to gas diffusion from the bulk gas to the membrane external surface can be ignored compared to other resistances [8]. Accordingly, the increase of the gas flow rate obviously cannot enhance the NO mass transfer rate. On the other hand, the membrane resistance depends on the membrane operation mode, i.e., non-wetted, wetted or partially wetted mode. The high gas flow rate raised the gas pressure outside the membrane fiber, thus pushing some water out from the fiber pores and alleviating the membrane wetting. This resulted in an increase in the NO mass transfer rate as shown in Fig. 2 because the wetting surface increases the membrane mass transfer resistance rapidly and significantly [9]. Despite the increase in the NO mass transfer rate, the NO residence time declined, which is unfavorable for the NO absorption. The competition of both effects resulted in a decrease in the NO removal efficiency, indicating that the unfavorable effect played the major role.

\section{Effect of absorbent flow rate}

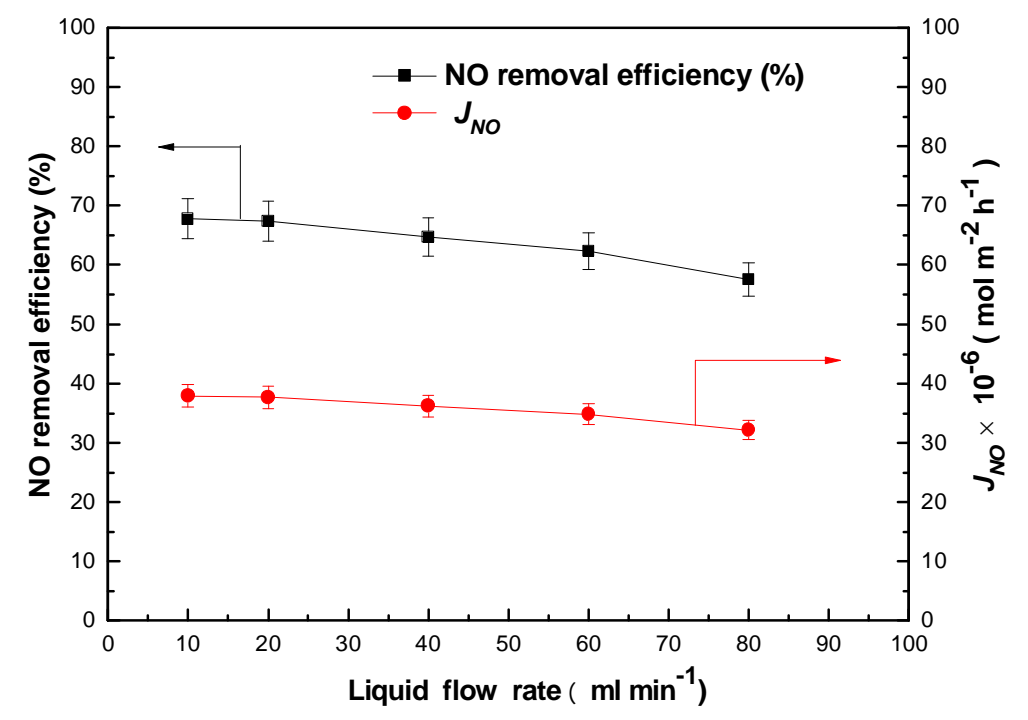

Fig. 3. Effect of absorbent flow rate on the NO removal efficiency and NO mass transfer rate (feed gas of $184.8 \mathrm{ppm} \mathrm{NO}$ balanced with $\mathrm{N}_{2}$; feed gas flowrate of $100 \mathrm{ml} \mathrm{min}^{-1}$; absorbent of $0.2 \mathrm{wt}$. \% $\mathrm{H}_{2} \mathrm{O}_{2}$ and 5 wt.\% NaCl; absorption temperature of $323 \mathrm{~K}$ ).

Fig. 3 demonstrates the effect of absorbent flow rate on the NO absorption for the PP membrane. When the absorbent flow rate increased from 10 to $80 \mathrm{ml} \mathrm{min}^{-1}$, both NO removal efficiency and NO mass transfer rate decreased rapidly from $67.8 \%$ to $37.9 \%$ and from $5.75 \times 10^{-5}$ to $3.22 \times 10^{-5} \mathrm{~mol} \mathrm{~m}^{-2}$ $\mathrm{h}^{-1}$, respectively. In the case of a liquid flowing through lumen of the hollow fiber, the Sherwood number of liquid phase $\left(S h_{1}\right)$ can be calculated in Eqs. (4): 


$$
S h_{l}=\left\{\begin{array}{cc}
k_{l} d_{i} / D_{l}=3.67 & G z<10 \\
S h_{l}=\left(3.67^{3}+1.62^{3} G z\right)^{1 / 3} & 10<G z<20 \\
S h_{l}=1.62(G z)^{1 / 3} & G z>20
\end{array}\right.
$$

For the PP membrane with absorbent flow rates from 10 to $80 \mathrm{ml} \mathrm{min}^{-1}$, the corresponding Reynolds number ranged from 0.27 to 2.18 and the Graetz number $(\mathrm{Gz})$ was far less than 1. A constant $S h_{1}$ of 3.67 was obtained over the membrane length in accordance with Eqs.1. Therefore, the increase in absorbent flow rate from 10 to $50 \mathrm{ml} \mathrm{min}^{-1}$ had no influence on $S h_{1}$ and $k_{1}$. On the other hand, the liquid pressure inside the membrane fiber increased with a rise in absorbent flow rate, pushing more water into the fiber pores and enhancing the membrane wetting. This results in a decrease in the NO mass transfer rate as shown in Fig. 4 because the wetting condition increases the membrane mass transfer resistance rapidly and significantly [11].

\section{Effect of $\mathrm{H}_{2} \mathrm{O}_{2}$ concentrations}

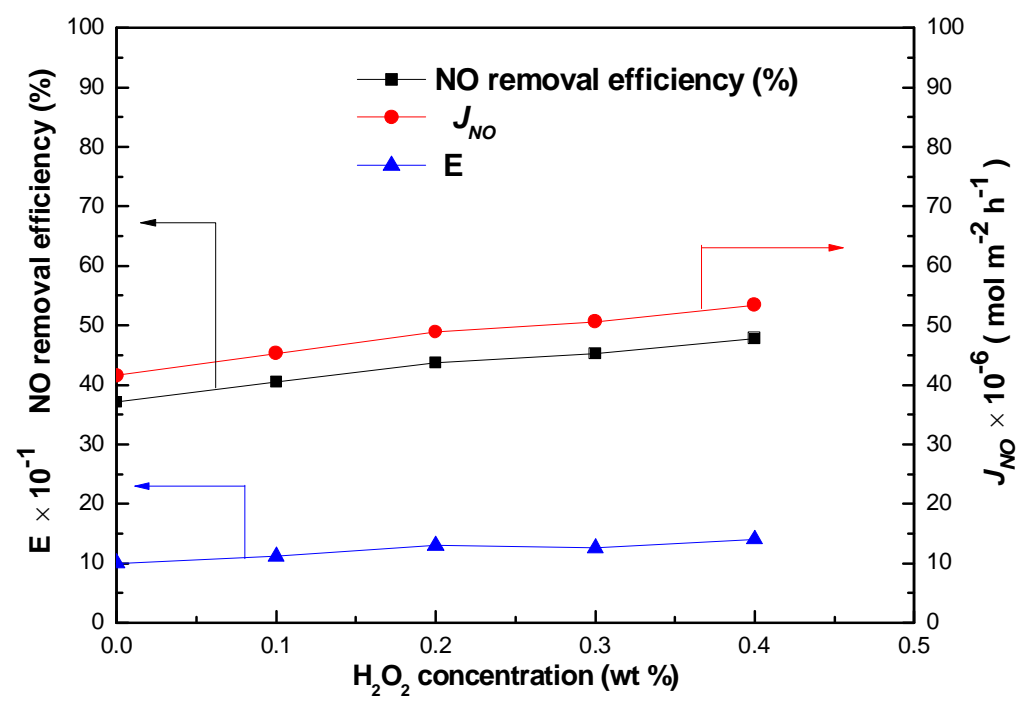

Fig. 4. Effect of $\mathrm{H}_{2} \mathrm{O}_{2}$ concentration on the $\mathrm{NO}$ removal efficiency and $\mathrm{NO}$ mass transfer rate (feed gas of $184.8 \mathrm{ppm} \mathrm{NO}$ balanced with $\mathrm{N}_{2}$; feed gas flowrate of $200 \mathrm{ml} \mathrm{min}{ }^{-1}$; absorbent of $\mathrm{H}_{2} \mathrm{O}_{2}$ and 5 wt.\% NaCl; absorbent flow rate of $40 \mathrm{ml} \mathrm{min}^{-1}$; absorption temperature of $323 \mathrm{~K}$ ).

The effect of $\mathrm{H}_{2} \mathrm{O}_{2}$ concentration was illustrated in Fig. 4. When the $\mathrm{H}_{2} \mathrm{O}_{2}$ concentration rose from 0 to $0.4 \mathrm{wt}$. \%, both NO removal efficiency and NO mass transfer rate increased slightly from $37.2 \%$ to $47.8 \%$ and from $4.15 \times 10^{-5}$ to $5.35 \times 10^{-5} \mathrm{~mol} \mathrm{~m} \mathrm{~m}^{-2} \mathrm{~h}^{-1}$, respectively. The enhancement factor $\mathrm{E}$ describes the effect of a chemical reaction on the mass transfer rate. Generally, E is defined as the ratio of the absorption flux in the presence of a chemical reaction (chemical absorption) to the absorption flux in the absence of a chemical reaction (physical absorption) for identical mass transfer force $\mathrm{E}$, as calculated in accordance with the equations reported by Mansourizadeh et al. [7], rose from 1.0 to 1.40 with the increase in $\mathrm{H}_{2} \mathrm{O}_{2}$ concentration from 0 to 0.4 wt.\%.

\section{Effect of $\mathrm{SO}_{2}$ concentration}

As shown in Fig. 5, the NO removal efficiency and NO mass transfer rate decreased slightly first and then increased along with the increase of $\mathrm{SO}_{2}$ concentration from 0 to $320 \mathrm{ppm}$. The lowest removal efficiency and mass transfer rate are $51.9 \%$ and $5.63 \times 10^{-5} \mathrm{~mol} \mathrm{~m}^{-2} \mathrm{~h}^{-1}$ when the $\mathrm{SO}_{2}$ concentration is $130 \mathrm{ppm}$. $\mathrm{SO}_{2}$ exhibited a higher solubility than NO. Thus more $\mathrm{SO}_{2}$ can be oxidized by $\mathrm{H}_{2} \mathrm{O}_{2}$ than NO in the feed stream. Due to the competition of oxidation, the addition of $\mathrm{SO}_{2}$ is unfavorable for the $\mathrm{NO}$ removal. On the other hand, the $\mathrm{pH}$ value of the absorbent in the case with the addition of $\mathrm{SO}_{2}$ is higher than that without $\mathrm{SO}_{2}$ because the solubility and oxidation of $\mathrm{SO}_{2}$ in the absorbent forming $\mathrm{H}_{2} \mathrm{SO}_{3}$ and $\mathrm{H}_{2} \mathrm{SO}_{4}$. The decline of $\mathrm{pH}$ can strengthen the $\mathrm{H}_{2} \mathrm{O}_{2}$ oxidation ability since it provides high concentration of $\mathrm{H}^{+}$and is favorable for the reaction. The high $\mathrm{H}_{2} \mathrm{O}_{2}$ oxidation 
ability suggests a high value of enhancement factor E, which is favorable for the NO removal. The two conflicting effects gave rise to the change of NO removal efficiency and NO mass transfer rate with the addition of $\mathrm{SO}_{2}$ as illustrated in Fig. 5.

The $\mathrm{SO}_{2}$ concentration at the absorber outlet kept below the $\mathrm{SO}_{2}$ detector tube detection limit of $100 \mathrm{ppb}$ with its removal efficiency of almost $100 \%$ throughout the whole operation time. $\mathrm{The}^{\mathrm{SO}_{2}}$ concentration below $100 \mathrm{ppb}$ is much lower than that required by $\mathrm{SO}_{2}$ emission standard for flue gas from new-built coal fired power plant (35 ppm by China government [12]). It is also below the National Ambient Air Quality Standards for $\mathrm{SO}_{2}$ proposed by United States Environmental Protection Agency (EPA) as follows: sulfur concentrations of $140 \mathrm{ppb}$ measured over $24 \mathrm{~h}$ [13]. Therefore, this co-capture of $\mathrm{NO}$ and $\mathrm{SO}_{2}$ could play an important role in further desulfuration, most likely alleviating the burden of desulfuration to some extent. This is an additional benefit of NO removal in our case.

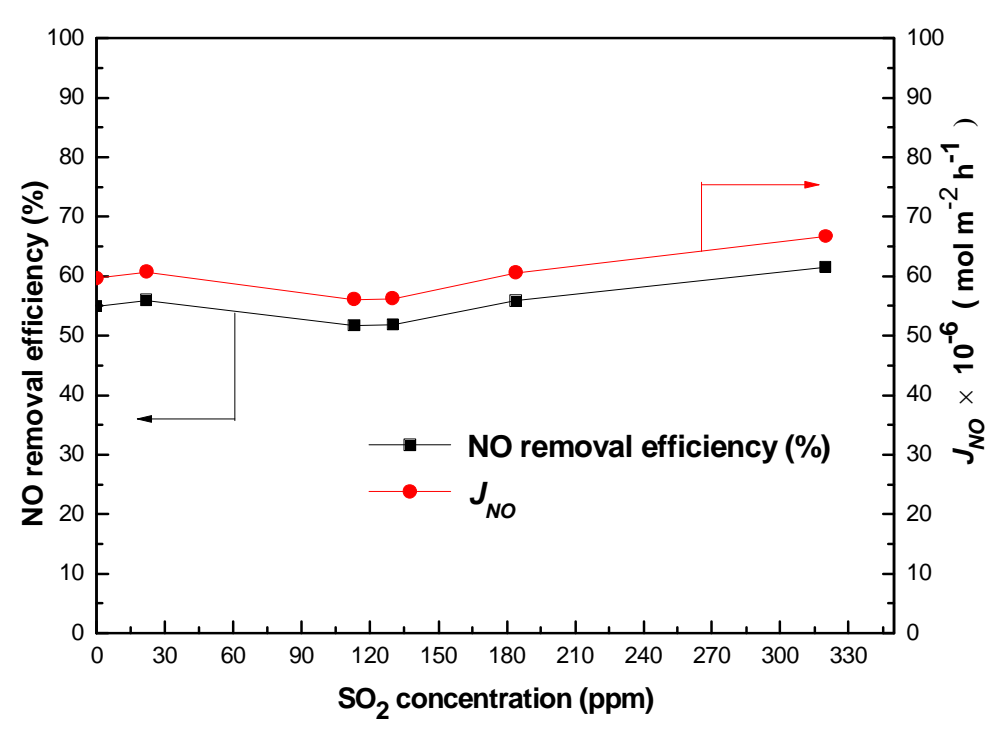

Fig. 5. Effect of $\mathrm{SO}_{2}$ concentration on the NO removal efficiency and NO mass transfer rate (feed gas of $184.8 \mathrm{ppm} \mathrm{NO}$ balanced with $\mathrm{N}_{2}$ and $\mathrm{SO}_{2}$; feed gas flowrate of $200 \mathrm{ml} \mathrm{min}^{-1}$; absorbent of 0.4 wt. $\% \mathrm{H}_{2} \mathrm{O}_{2}$ and $30 \mathrm{wt} . \% \mathrm{NaCl}$; absorbent flow rate of $40 \mathrm{ml} \mathrm{min}^{-1}$, absorption temperature of $333 \mathrm{~K}$ ). 


\section{Effect of operation time with circulatory absorbent}

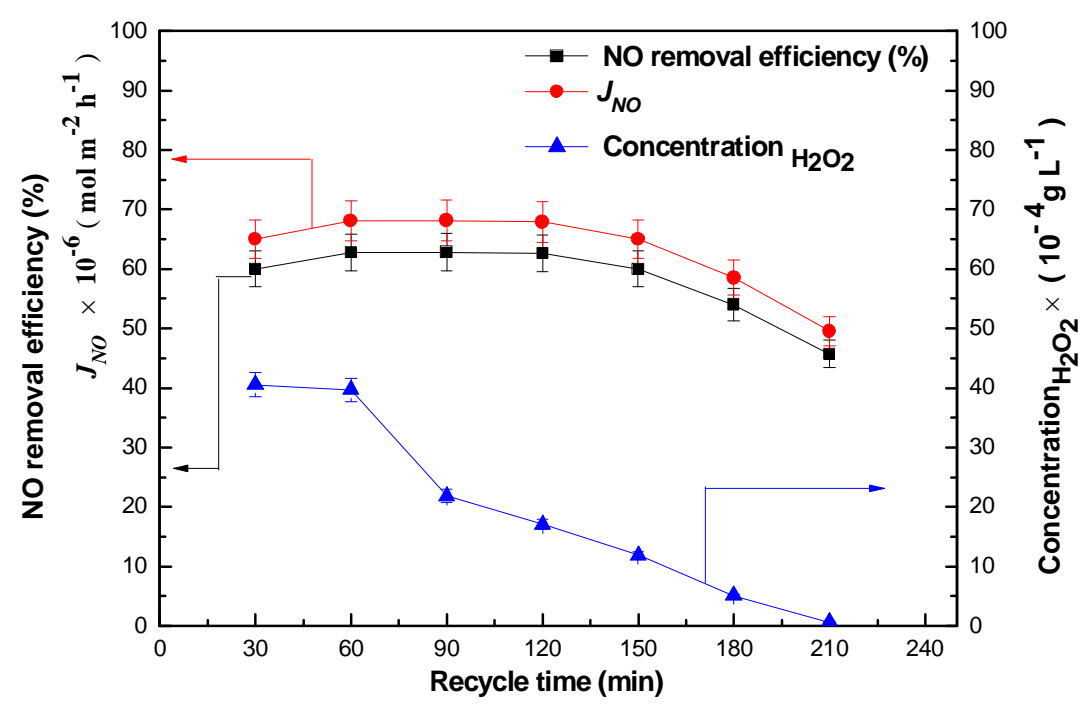

Fig. 6. Effect of operation time on the NO removal efficiency and NO mass transfer rate with circulatory absorbent (feed gas of $184.8 \mathrm{ppm} \mathrm{NO}$; feed gas flow rate of $200 \mathrm{ml} \mathrm{min}^{-1}$; absorbent of

0.4 wt. $\% \mathrm{H}_{2} \mathrm{O}_{2}$ and 30 wt. $\% \mathrm{NaCl}$; absorbent volume of $2 \mathrm{~L}$; absorbent flow rate of $40 \mathrm{ml} \mathrm{min}^{-1}$, absorption temperature of $333 \mathrm{~K}$ ).

The effect of operation time on the NO removal efficiency is shown in Fig. 6. The NO removal efficiency and NO mass transfer rate decreased gradually from $60.0 \%$ to $45.7 \%$ and from $6.50 \times 10^{-5}$ to $4.96 \times 10^{-5} \mathrm{~mol} \mathrm{~m}^{-2} \mathrm{~h}^{-1}$ when the operation time increased from 30 to $210 \mathrm{~min}$. This is because the $\mathrm{H}_{2} \mathrm{O}_{2}$ concentration declined from $0.398 \mathrm{wt} . \%$ to $0.006 \mathrm{wt}$. \% accordingly within this time interval. In the practical application, the $\mathrm{H}_{2} \mathrm{O}_{2}$ concentration of the circulatory absorbent can be stabilized by compensating the loss of $\mathrm{H}_{2} \mathrm{O}_{2}$ to ensure a high and steady $\mathrm{NO}$ removal efficiency. The mole ratio of the consumed $\mathrm{H}_{2} \mathrm{O}_{2}$ to the removed $\mathrm{NO}$ is 0.37 based on the data from 60 to 120 min of operation time as shown in Fig. 6.

\section{Conclusions}

By using a PP hollow fiber membrane contactor and $\mathrm{H}_{2} \mathrm{O}_{2}$ aqueous solution with the addition of $\mathrm{NaCl}$, a new denitration method was proposed in this work. We demonstrated that the NO removal efficiency achieved $91.2 \%$ under the following condition: NO concentration of $184.8 \mathrm{ppm}$, absorbent of 0.2 wt. $\% \mathrm{H}_{2} \mathrm{O}_{2}$ and $5 \mathrm{wt} . \% \mathrm{NaCl}$ in water, gas flow rate of $50 \mathrm{ml} \mathrm{min}^{-1}$, absorbent flow rate of $40 \mathrm{ml}$ $\mathrm{min}^{-1}$, and absorption temperature of $323 \mathrm{~K}$. The $\mathrm{SO}_{2}$ concentration at the outlet of the contactor kept below $100 \mathrm{ppb}$ with the removal efficiency of almost 100\% throughout the whole operation time, and this concentration is much lower than the $\mathrm{SO}_{2}$ emission standard for the flue gas from a new-built coal fired power plant. The co-capture feature of $\mathrm{NO}$ and $\mathrm{SO}_{2}$ could play an important role in further desulfuration, most likely alleviating the burden of desulfuration to some extent. The proposed denitration method is featured with high NO removal efficiency, medium investment and low removal costs and alleviating $\mathrm{SO}_{2}$ removal burden, and thus provides a promising alternative to the current mainstream technologies for flue gas denitration.

\section{Acknowledgements}

This work was financially supported by the China Natural Science Foundation (Contract No. 21176069, 21476073 and 91434110) and the Fundamental Research Funds for the Central 
Universities (WG1213011, WA1516005). SZ acknowledges the support of Fok Ying Tong Education Foundation (151069).

\section{References}

[1] Cooper CD, Clausen CA III, Pettey L, Collins MM, Maria PF. Investigation of Ultraviolet Light-Enhanced H2O2 Oxidation of NOx Emissions. J Environ Eng 2002; 128:68-72.

[2] Limvoranusorn P, Cooper CD, Dietz JD, Clausen CA, Pettey L, Collins MM. Kinetic modeling of the gas-phase oxidation of nitric oxide using hydrogen peroxide. J Environ Eng 2005; 131:518-25.

[3] Lv YX, Yu XH, Tu ST, Yan JY, Dahlquist E. Wetting of polypropylene hollow fiber membrane contactors. J MembrSci 2010; 362:444-52.

[4] Lv YX, Yu XH, Jia JJ, Tu ST, Yan JY, Dahlquist E. Fabrication and characterization of super hydrophobic polypropylene hollow fiber membranes for carbon dioxide absorption. Appl Energy 2012; 90:167-74.

[5] Yang J, Yu XH, Yan JY, Tu ST, Dahlquist E. Effects of SO2 on CO2 capture using a hollow fiber membrane contactor. Appl Energy 2013; 112:755-64.

[6] Lv YX, Yu XH, Tu ST, Yan JY, Dahlquist E. Experimental studies on simultaneous removal of $\mathrm{CO} 2$ and $\mathrm{SO} 2$ in a polypropylene hollow fiber membrane contactor. Appl Energy 2012; 97: 283-8.

[7] Mansourizadeh A, Ismail AF, Hollow fiber gas-liquid membrane contactors for acid gas capture: a review, J. Hazard Mater 2009; 171:38-53.

[8] Rangwala HA, Absorption of carbon dioxide into aqueous solutions using hollow fiber membrane contactors, J MembrSci 1996; 112:229-40.

[9] Wang R, Zhang HY, Feron PHM, Liang DT, Influence of membrane wetting on CO2 capture in microporous hollow fiber membrane contactors, Sep PurifTechnol 2005;46:33-40.

[10] Chowdhuri S, Chandra A. Molecular dynamics simulations of aqueous $\mathrm{NaCl}$ and $\mathrm{KCl}$ solutions: Effects of ion concentration on the single-particle, pair, and collective dynamical properties of ions and water molecules. J ChemPhys, 2001; 115:3732-41.

[11] Waisman E, Lebowitz JL. Mean Spherical Model Integral Equation for Charged Hard Spheres I. Method of Solution. J ChemPhys, 1972; 56:3093-9.

[12] Emission standard of air pollution for thermal power plants. National Institute of Standards of the People's Republic of China; 2011.

[13]Hamilton S, Obispo C. Emissions standards and ambient environmental quality standards in stochastic receiving media; 2010. <agecon.ucdavis.edu>. 